4

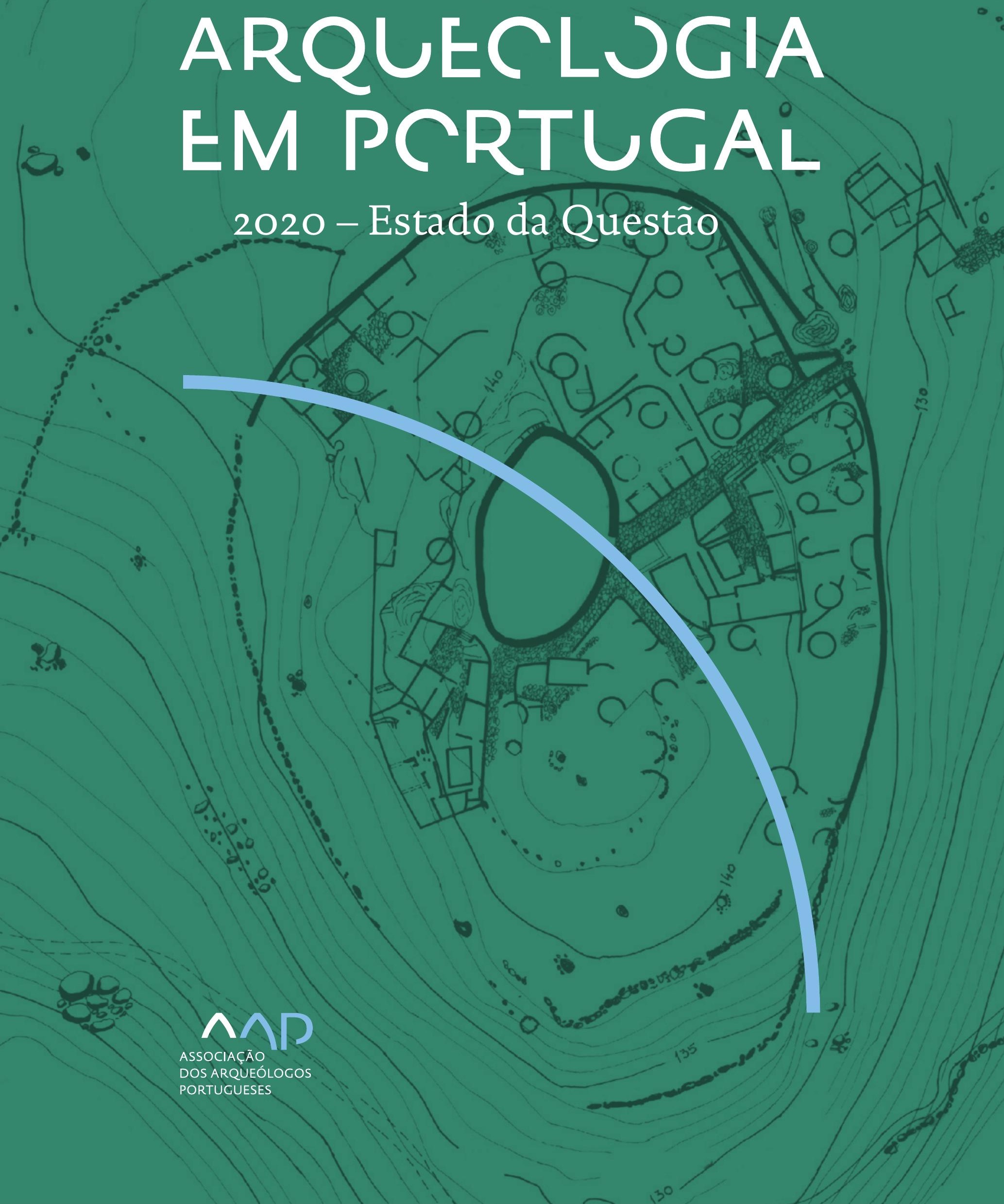


Coordenação editorial: José Morais Arnaud, César Neves e Andrea Martins Design gráfico: Flatland Design

AAP - ISBN: 978-972-9451-89-8

CITCEM - ISBN: 978-989-8970-25-1

Associação dos Arqueólogos Portugueses e CITCEM

Lisboa, 2020

O conteúdo dos artigos é da inteira responsabilidade dos autores. Sendo assim a Associação dos Arqueólogos Portugueses declina qualquer responsabilidade por eventuais equívocos ou questões de ordem ética e legal.

Desenho de capa:

Planta do castro de Monte Mozinho (Museu Municipal de Penafiel).

\section{$\hat{\wedge} \mathrm{P}$}

DOS ARQUEÓLOGOS PORTUGUESES

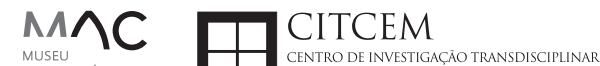
MUSEU
ARQUELLÓGICO
DO CARMO
U.PORTO

FLUP FACULDADE DE LETRAS
UNIVERSIDADE DO PORTO

Apoio

EC para a Ciência 


\section{Índice}

15 Prefácio

José Morais Arnaud

\section{Historiografia e Teoria}

17 Território, comunidade, memória e emoção: a contribuição da história da arqueologia (algumas primeiras e breves reflexões)

Ana Cristina Martins

25 Como descolonizar a arqueologia portuguesa?

Rui Gomes Coelho

41 Arqueologia e Modernidade: uma revisitação pessoal e breve de alguns aspetos da obra homónima de Julian Thomas de 2004

Vítor Oliveira Jorge

57 Dados para a História das Mulheres na Arqueologia portuguesa, dos finais do século XIX aos inícios do século XX: números, nomes e tabelas

Filipa Dimas / Mariana Diniz

73 Retractos da arqueologia portuguesa na imprensa: (in)visibilidades no feminino

Catarina Costeira / Elsa Luís

85 Arqueologia e Arqueólogos no Norte de Portugal Jacinta Bugalhão

101 Vieira Guimarães (1864-1939) e a arqueologia em Tomar: uma abordagem sobre o território e as gentes

João Amendoeira Peixoto / Ana Cristina Martins

115 Os memoráveis? A arqueologia algarvia na imprensa nacional e regional na presente centúria (2001-2019): características, visões do(s) passado(s) e a arqueologia

enquanto marca

Frederico Agosto / João Silva

129 A Evolução da Arqueologia Urbana e a Valorização Patrimonial no Barlavento Algarvio: Os casos de Portimão e Silves

Artur Mateus / Diogo Varandas / Rafael Boavida

\section{Gestão, Valorização e Salvaguarda do Património}

145 O Caderno Reivindicativo e as condições de trabalho em Arqueologia Miguel Rocha / Liliana Matias Carvalho / Regis Barbosa / Mauro Correia / Sara Simões / Jacinta Bugalhão / Sara Brito / Liliana Veríssimo Carvalho / Richard Peace / Pedro Peça / Cézer Santos

155 Os Estudos de Impacte Patrimonial como elemento para uma estratégia sustentável de minimização de impactes no âmbito de reconversões agrícolas Tiago do Pereiro

165 Salvaguarda de Património arqueológico em operações florestais: gestão e sensibilização Filipa Bragança / Gertrudes Zambujo / Sandra Lourenço / Belém Paiva / Carlos Banha / Frederico Tatá Regala / Helena Moura / Jacinta Bugalhão / João Marques / José Correia / Pedro Faria / Samuel Melro

179 Os valores do Património: uma investigação sobre os Sítios Pré-históricos de Arte Rupestre do Vale do Rio Côa e de Siega Verde José Paulo Francisco 
189 Conjugando recursos arqueológicos e naturais para potenciar as visitas ao Geoparque Litoral de Viana do Castelo (Noroeste de Portugal)

Hugo A. Sampaio / Ana M.S. Bettencourt / Susana Marinho / Ricardo Carvalhido

203 Áreas de Potencial Arqueológico na Região do Médio Tejo: Modelo Espacial Preditivo Rita Ferreira Anastácio / Ana Filipa Martins / Luiz Oosterbeek

223 Património Arqueológico e Gestão Territorial: O contributo da Arqueologia para a revisão do PDM de Avis

Ana Cristina Ribeiro

237 A coleção arqueológica do extinto Museu Municipal do Porto - Origens, Percursos e Estudos

Sónia Couto

251 Valpaços - uma nova carta arqueológica

Pedro Pereira / Maria de Fátima Casares Machado

263 Arqueologia na Cidade de Peniche

Adriano Constantino / Luís Rendeiro

273 Arqueologia Urbana: a cidade de Lagos como caso de Estudo Cátia Neto

285 Estratégias de promoção do património cultural subaquático nos Açores. O caso da ilha do Faial

José Luís Neto / José Bettencourt / Luís Borges / Pedro Parreira

297 Carta Arqueológica da Cidade Velha: Uma primeira abordagem

Jaylson Monteiro / Nireide Tavares / Sara da Veiga / Claudino Ramos / Edson Brito /

Carlos Carvalho / Francisco Moreira / Adalberto Tavares

311 Antropologia Virtual: novas metodologias para a análise morfológica e funcional Ricardo Miguel Godinho / Célia Gonçalves

\section{Didáctica da Arqueologia}

327 Como os projetos de Arqueologia podem contribuir para uma comunidade culturalmente mais consciente Alexandra Figueiredo / Claúdio Monteiro / Adolfo Silveira / Ricardo Lopes

337 Educação Patrimonial - Um cidadão esclarecido é um cidadão ativo! Ana Paula Almeida

351 A aproximação da Arqueologia à sala de aula: um caso de estudo no $3^{\circ}$ ciclo do Ensino Básico Luís Serrão Gil

363 Arqueologia 3.o - Pensar e comunicar a Arqueologia para um futuro sustentável Mónica Rolo

377 “Conversa de Arqueólogos" - Divulgar a Arqueologia em tempos de Pandemia Diogo Teixeira Dias

389 Escola Profissional de Arqueologia: desafios e oportunidades Susana Nunes / Dulcineia Pinto / Júlia Silva / Ana Mascarenhas

399 Os Museus de Arqueologia e os Jovens: a oferta educativa para o público adolescente Beatriz Correia Barata / Leonor Medeiros

411 O museu universitário como mediador entre a ciência e a sociedade: o exemplo da secção de arqueologia no Museu de História Natural e da Ciência da Universidade do Porto (MHNC-UP)

Rita Gaspar 
421 Museu de Lanifícios: Real Fábrica de Panos. Atividades no âmbito da Arqueologia Beatriz Correia Barata / Rita Salvado

427 Arqueologia Pública e o caso da localidade da Mata (Torres Novas) Cláudia Manso / Ana Rita Ferreira / Cristiana Ferreira / Vanessa Cardoso Antunes

431 Do sítio arqueológico ao museu: um percurso (também) didático Lídia Fernandes

447 Estão todos convidados para a Festa! E para dançar também... O projecto do Serviço Educativo do Museu Arqueológico do Carmo na $5^{\underline{a}}$ Edição da Festa da Arqueologia Rita Pires dos Santos

459 O “Clã de Carenque”, um projeto didático de arqueologia Eduardo Gonzalez Rocha

469 Mediação cultural: peixe que puxa carroça nas Ruínas Romanas de Troia Inês Vaz Pinto / Ana Patrícia Magalhães / Patrícia Brum / Filipa Santos

481 Didática Arqueológica, experiências do Projeto Mértola Vila Museu Maria de Fátima Palma / Clara Rodrigues / Susana Gómez / Lígia Rafael

\section{Arte Rupestre}

497 Os inventários de arte rupestre em Portugal Mila Simões de Abreu

513 O projeto FIRST-ART - conservação, documentação e gestão das primeiras manifestações de arte rupestre no Sudoeste da Península Ibérica: as grutas do Escoural e Maltravieso Sara Garcês / Hipólito Collado / José Julio García Arranz / Luiz Oosterbeek / António Carlos Silva / Pierluigi Rosina / Hugo Gomes / Anabela Borralheiro Pereira / George Nash / Esmeralda Gomes / Nelson Almeida / Carlos Carpetudo

523 Trabalhos de documentação de arte paleolítica realizados no âmbito do projeto PalæoCôa André Tomás Santos / António Fernando Barbosa / Luís Luís / Marcelo Silvestre / Thierry Aubry

537 Imagens fantasmagóricas, silhuetas elusivas: as figuras humanas na arte do Paleolítico Superior da região do Côa Mário Reis

$55^{1}$ Os motivos zoomórficos representados nas placas de tear de Vila Nova de São Pedro (Azambuja, Portugal) Andrea Martins / César Neves / José M. Arnaud / Mariana Diniz

571 Arte Rupestre do Monte de Góios (Lanhelas, Caminha). Síntese dos resultados dos trabalhos efectuados em 2007-2009 Mário Varela Gomes

599 Gravuras rupestres de barquiformes no Monte de S. Romão, Guimarães, Noroeste de Portugal Daniela Cardoso

613 Círculos segmentados gravados na Bacia do Rio Lima (Noroeste de Portugal): contributos para o seu estudo Diogo Marinho / Ana M.S. Bettencourt / Hugo Aluai Sampaio

631 Equídeos gravados no curso inferior do Rio Mouro, Monção (NW Portugal). Análise preliminar Coutinho, L.M. / Bettencourt, A.M.S / Sampaio, Hugo A.S

645 Paletas na Arte Rupestre do Noroeste de Portugal. Inventário preliminar Bruna Sousa Afonso / Ana M. S. Bettencourt / Hugo A. Sampaio 


\section{Pré-História}

661 O projeto Miño/Minho: balanço de quatro anos de trabalhos arqueológicos Sérgio Monteiro-Rodrigues / João Pedro Cunha-Ribeiro / Eduardo Méndez-Quintas / Carlos Ferreira / Pedro Xavier / José Meireles / Alberto Gomes / Manuel Santonja / Alfredo Pérez-González

677 A ocupação paleolítica da margem esquerda do Baixo Minho: a indústria lítica do sítio de Pedreiras 2 (Monção, Portugal) e a sua integração no contexto regional Carlos Ferreira / João Pedro Cunha-Ribeiro / Sérgio Monteiro-Rodrigues / Eduardo Méndez-Quintas / Pedro Xavier / José Meireles / Alberto Gomes / Manuel Santonja / Alfredo Pérez-González

693 O sítio acheulense do Plistocénico médio da Gruta da Aroeira Joan Daura / Montserrat Sanz / Filipa Rodrigues / Pedro Souto / João Zilhão

703 As sociedades neandertais no Barlavento algarvio: modelos preditivos com recurso aos SIG

Daniela Maio

715 A utilização de quartzo durante o Paleolítico Superior no território dos vales dos rios Vouga e Côa

Cristina Gameiro / Thierry Aubry / Bárbara Costa / Sérgio Gomes / Luís Luís / Carmen Manzano / André Tomás Santos

733 Uma perspetiva diacrónica da ocupação do concheiro do Cabeço da Amoreira (Muge, Portugal) a partir da tecnologia lítica Joana Belmiro / João Cascalheira / Célia Gonçalves

745 Novos dados sobre a Pré-história Antiga no concelho de Palmela. A intervenção arqueológica no sítio do Poceirão I

Michelle Teixeira Santos

757 Problemas em torno de Datas Absolutas Pré-Históricas no Norte do Alentejo Jorge de Oliveira

771 Povoamento pré-histórico nas áreas montanhosas do NO de Portugal: o Abrigo 1 de Vale de Cerdeira Pedro Xavier / José Meireles / Carlos Alves

783 Apreciação do povoamento do Neolítico Inicial na Baixa Bacia do Douro. A Lavra I (Serra da Aboboreira) como caso de estudo Maria de Jesus Sanches

797 O Processo de Neolitização na Plataforma do Mondego: os dados do Sector C do Outeiro dos Castelos de Beijós (Carregal do Sal)

João Carlos de Senna-Martinez / José Manuel Quintã Ventura / Andreia Carvalho / Cíntia Maurício

823 Novos trabalhos na Lapa da Bugalheira (Almonda, Torres Novas) Filipa Rodrigues / Pedro Souto / Artur Ferreira / Alexandre Varanda / Luís Gomes / Helena Gomes / João Zilhão

837 A pedra polida e afeiçoada do sítio do Neolítico médio da Moita do Ourives (Benavente, Portugal)

César Neves

857 Casal do Outeiro (Encarnação, Mafra): novos contributos para o conhecimento do povoamento do Neolítico final na Península de Lisboa.

Cátia Delicado / Carlos Maneira e Costa / Marta Miranda / Ana Catarina Sousa

873 Stresse infantil, morbilidade e mortalidade no sítio arqueológico do Neolítico Final/ Calcolítico ( $4^{\circ}$ e $3^{\circ}$ milénio a.C.) do Monte do Carrascal 2 (Ferreira do Alentejo, Beja) Liliana Matias de Carvalho / Sofia N. Wasterlain 
885 Come together: O Conjunto Megalítico das Motas (Monção, Viana do Castelo) e as expressões Campaniformes do Alto Minho Ana Catarina Basílio / Rui Ramos

899 Trabalhos arqueológicos no sítio Calcolítico da Pedreira do Poio Carla Magalhães / João Muralha / Mário Reis / António Batarda Fernandes

913 O sítio arqueológico de Castanheiro do Vento. Da arquitectura do sítio à arquitectura de um território João Muralha Cardoso

925 Estudo zooarqueológico das faunas do Calcolítico final de Vila Nova de São Pedro (Azambuja, Portugal): Campanhas de 2017 e 2018 Cleia Detry / Ana Catarina Francisco / Mariana Diniz / Andrea Martins / César Neves / José Morais Arnaud

943 As faunas depositadas no Museu Arqueológico do Carmo provenientes de Vila Nova de São Pedro (Azambuja): as campanhas de 1937 a 1967 Ana Catarina Francisco / Cleia Detry / César Neves / Andrea Martins / Mariana Diniz / José Morais Arnaud

959 Análise funcional de material lítico em sílex do castro de Vila Nova de S. Pedro (Azambuja, Portugal): uma primeira abordagem Rafael Lima

971 O recinto da Folha do Ouro 1 (Serpa) no contexto dos recintos de fossos calcolíticos alentejanos

António Carlos Valera / Tiago do Pereiro / Pedro Valério / António M. Monge Soares

\section{Proto-História}

987 Produção de sal marinho na Idade do Bronze do noroeste Português. Alguns dados para uma reflexão

Ana M. S. Bettencourt / Sara Luz / Nuno Oliveira / Pedro P. Simões / Maria Isabel C. Alves / Emílio Abad-Vidal

1001 A estátua-menir do Pedrão ou de São Bartolomeu do Mar (Esposende, noroeste de Portugal) no contexto arqueológico da fachada costeira de entre os rios Neiva e Cávado Ana M. S. Bettencourt / Manuel Santos-Estévez / Pedro Pimenta Simões / Luís Gonçalves

1015 O Castro do Muro (Vandoma/Baltar, Paredes) - notas para uma biografia de ocupação da Idade do Bronze à Idade Média

Maria Antónia D. Silva / Ana M. S. Bettencourt / António Manuel S. P. Silva / Natália Félix

1031 Do Bronze Final à Idade Média - continuidades e hiatos na ocupação de Povoados em Oliveira de Azeméis João Tiago Tavares / Adriaan de Man

1041 As faunas do final da Idade do Bronze no Sul de Portugal: leituras desde o Outeiro do Circo (Beja)

Nelson J. Almeida / Íris Dias / Cleia Detry / Eduardo Porfírio / Miguel Serra

1055 A Espada do Monte das Oliveiras (Serpa) - uma arma do Bronze Pleno do Sudoeste Rui M. G. Monge Soares / Pedro Valério / Mariana Nabais / António M. Monge Soares

1065 São Julião da Branca (Albergaria-a-Velha) - Investigação e valorização de um povoado do Bronze Final

António Manuel S. P. Silva / Paulo A. P. Lemos / Sara Almeida e Silva / Edite Martins de Sá

1083 Do castro de S. João ao Mosteiro de Santa Clara: notícia de uma intervenção arqueológica, em Vila do Conde Rui Pinheiro 
1095 O castro de Ovil (Espinho), um quarto de século de investigação - resultados e questões em aberto

Jorge Fernando Salvador / António Manuel S. P. Silva

1111 O Castro de Salreu (Estarreja), um povoado proto-histórico no litoral do Entre Douro e Vouga

Sara Almeida e Silva / António Manuel S. P. Silva / Paulo A. P. Lemos / Edite Martins de Sá

1127 Castro de Nossa Senhora das Necessidades (Sernancelhe): uma primeira análise artefactual Telma Susana O. Ribeiro

${ }_{1141}$ A cividade de Bagunte. O estado atual da investigação Pedro Brochado de Almeida

1153 Zoomorfos na cerâmica da Idade do Ferro no NW Peninsular: inventário, cronologias e significado Nuno Oliveira / Cristina Seoane

1163 Vasos gregos em Portugal: diferentes maneiras de contar a história do intercâmbio cultural na Idade do Ferro

Daniela Ferreira

1175 Os exotica da necrópole da Idade do Ferro do Olival do Senhor dos Mártires (Alcácer do Sal) no seu contexto regional

Francisco B. Gomes

\section{Antiguidade Clássica e Tardia}

1191 O uso de madeira como combustível no sítio da Quinta de Crestelos (Baixo Sabor): da Idade do Ferro à Romanização Filipe Vaz / João Tereso / Sérgio Simões Pereira / José Sastre / Javier Larrazabal Galarza / Susana Cosme / José António Pereira / Israel Espi

1207 Cultivos de Época Romana no Baixo Sabor: continuidade em tempos de mudança? João Pedro Tereso / Sérgio Simões Pereira / Filipe Santos / Luís Seabra / Filipe Vaz

1221 A casa romana na Hispânia: aplicação dos modelos itálicos nas províncias ibéricas Fernanda Magalhães / Diego Machado / Manuela Martins

1235 As pinturas murais romanas da Rua General Sousa Machado, n. ${ }^{5}$ 1, Chaves José Carvalho

1243 Trás do Castelo (Vale de Mir, Pegarinhos, Alijó) - Uma exploração agrícola romana do Douro

Tony Silvino / Pedro Pereira

1255 A sequência de ocupação no quadrante sudeste de Bracara Augusta: as transformações de uma unidade doméstica Lara Fernandes / Manuela Martins

1263 Os Mosaicos com decoração geométrica e geométrico-vegetalista dos sítios arqueológicos da área do Conuentus Bracaraugustanus. Novas abordagens quanto à conservação, restauro, decoração e datação Maria de Fátima Abraços / Licínia Wrench

1277 “Casa Romana” do Castro de São Domingos (Cristelos, Lousada): Escavação, Estudo e Musealização Paulo André de P. Lemos

1291 A arqueobotânica no Castro de Guifões (Matosinhos, Noroeste de Portugal): O primeiro estudo carpológico

Luís Seabra / Andreia Arezes / Catarina Magalhães / José Varela / João Pedro Tereso 
1305 Um Horreum Augustano na Foz do Douro (Monte do Castelo de Gaia, Vila Nova de Gaia) Rui Ramos

1311 Ponderais romanos na Lusitânia: padrões, formas, materiais e contextos de utilização Diego Barrios Rodríguez

1323 Um almofariz centro-itálico na foz do Mondego

Marco Penajoia

1335 Estruturas romanas de Carnide - Lisboa Luísa Batalha / Mário Monteiro / Guilherme Cardoso

1347 O contexto funerário do sector da "necrópole NO" da Rua das Portas de S. Antão (Lisboa): o espaço, os artefactos, os indivíduos e a sua interconectividade na interpretação do passado Sílvia Loja, José Carlos Quaresma, Nelson Cabaço, Marina Lourenço, Sílvia Casimiro, Rodrigo Banha da Silva, Francisca Alves-Cardoso

${ }_{1361}$ Povoamento em época Romana na Amadora - resultados de um projeto pluridisciplinar Gisela Encarnação / Vanessa Dias

1371 A Arquitectura Residencial em Mirobriga (Santiago do Cacém): contributo a partir de um estudo de caso Filipe Sousa / Catarina Felício

${ }_{1385}$ O fim do ciclo. Saneamento e gestão de resíduos nos edifícios termais de Mirobriga (Santiago do Cacém)

Catarina Felício / Filipe Sousa

1399 Balsa, Topografia e Urbanismo de uma Cidade Portuária Vítor Silva Dias / João Pedro Bernardes / Celso Candeias / Cristina Tété Garcia

1413 No Largo das Mouras Velhas em Faro (2017): novas evidências da necrópole norte de Ossonoba e da sua ocupação medieval Ricardo Costeira da Silva / Paulo Botelho / Fernando Santos / Liliana Nunes

1429 Instrumentos de pesca recuperados numa fábrica de salga em Ossonoba (Faro) Inês Rasteiro / Ricardo Costeira da Silva / Paulo Botelho

1439 A Necrópole Romana do Eirô, Duas Igrejas (Penafiel): intervenção arqueológica de 2016 Laura Sousa / Teresa Soeiro

1457 Ritual, descarte ou afetividade? A presença de Canis lupus familiaris na Necrópole Noroeste de Olisipo (Lisboa)

Beatriz Calapez Santos / Sofia Simões Pereira / Rodrigo Banha da Silva / Sílvia Casimiro / Cleia Detry / Francisca Alves Cardoso

1467 Dinâmicas económicas em Bracara na Antiguidade Tardia Diego Machado / Manuela Martins / Fernanda Magalhães / Natália Botica

1479 Cerâmicas e Vidros da Antiguidade Tardia do Edifício sob a Igreja do Bom Jesus (Vila Nova de Gaia) Joaquim Filipe Ramos

1493 Novos contributos para a topografia histórica de Mértola no período romano e na Antiguidade Tardia Virgílio Lopes

\section{8. Época Medieval}

1511 Cerâmicas islâmicas no Garb setentrional "português": algumas evidências e incógnitas Constança dos Santos / Helena Catarino / Susana Gómez / Maria José Gonçalves / Isabel Inácio / Gonçalo Lopes / Jacinta Bugalhão / Sandra Cavaco / Jaquelina Covaneiro / Isabel Cristina Fernandes / Ana Sofia Gomes 
1525 Contributo para o conhecimento da cosmética islâmica, em Silves, durante a Idade Média Rosa Varela Gomes

1537 Yábura e o seu território - uma análise histórico-arqueológica de Évora entre os séculos VIII-XII José Rui Santos

1547 A encosta sul do Castelo de Palmela - resultados preliminares da escavação arqueológica Luís Filipe Pereira / Michelle Teixeira Santos

1559 A igreja de São Lourenço (Mouraria, Lisboa): um conjunto de silos e de cerâmica medieval islâmica

Andreia Filipa Moreira Rodrigues

1571 O registo material de movimentações populacionais no Médio Tejo, durante os séculos XII-XIII. Dois casos de "sunken featured buildings", nos concelhos de Cartaxo e Torres Novas Marco Liberato / Helena Santos / Nuno Santos

1585 O nordeste transmontano nos alvores da Idade média. Notas para reflexão Ana Maria da Costa Oliveira

1601 Sepulturas escavadas na rocha do Norte de Portugal e do Vale do Douro: primeiros resultados do Projecto SER-NPVD

Mário Jorge Barroca / César Guedes / Andreia Arezes / Ana Maria Oliveira

1619 "Portucalem Castrum Novum" entre o Mediterrâneo e o Atlântico: o estudo dos materiais cerâmicos alto-medievais do arqueossítio da rua de D. Hugo, nํ. 5 (Porto) João Luís Veloso

1627 A Alta Idade Média na fronteira de Lafões: notas preliminares sobre a Arqueologia no Concelho de Vouzela

Manuel Luís Real / Catarina Tente

1641 Um conjunto cerâmico medieval fora de portas: um breve testemunho aveirense Susana Temudo

${ }_{1651}$ Os Lóios do Porto: uma perspetiva integrada no panorama funerário da Baixa Idade Média à Época Moderna em meios urbanos em Portugal

Ana Lema Seabra

1659 O Caminho Português Interior de Santiago como eixo viário na Idade Média Pedro Azevedo

1665 Morfologia Urbana: Um exercício em torno do Castelo de Ourém André Donas-Botto / Jaqueline Pereira

1677 Intervenção arqueológica na Rua Marquês de Pombal/Largo do Espírito Santo (Bucelas, Loures)

Florbela Estêvão / Nathalie Antunes-Ferreira / Dário Ramos Neves / Inês Lisboa

1691 O Cemitério Medieval do Poço do Borratém e a espacialidade funerária na cidade de Lisboa Inês Belém / Vanessa Filipe / Vasco Noronha Vieira / Sónia Ferro / Rodrigo Banha da Silva

1705 Um Espaço Funerário Conventual do séc. XV em Lisboa: o caso do Convento de São Domingos da Cidade Sérgio Pedroso / Sílvia Casimiro / Rodrigo Banha da Silva / Francisca Alves Cardoso

\section{9. Época Moderna e Contemporânea}

1721 Arqueologia Moderna em Portugal: algumas reflexões críticas em torno da quantificação de conjuntos cerâmicos e suas inferências históricas e antropológicas Rodrigo Banha da Silva / André Bargão / Sara da Cruz Ferreira

1733 Faianças de dois contextos entre os finais do século XVI e XVIII do Palácio dos Condes de Penafiel, Lisboa

Martim Lopes / Tomás Mesquita 
1747 Um perfil de consumo do século XVIII na foz do Tejo: O caso do Mercado da Ribeira, Lisboa Sara da Cruz Ferreira / Rodrigo Banha da Silva / André Bargão

1761 Os Cachimbos dos Séculos XVII e XVIII do Palácio Mesquitela e Convento dos Inglesinhos (Lisboa)

Inês Simão / Marina Pinto / João Pimenta / Sara da Cruz Ferreira / André Bargão / Rodrigo Banha da Silva

1775 "Tomar os fumos da erua que chamão em Portugal erua sancta». Estudo de Cachimbos provenientes da Rua do Terreiro do Trigo, Lisboa

Miguel Martins de Sousa / José Pedro Henriques / Vanessa Galiza Filipe

1787 Cachimbos de Barro Caulínitico da Sé da Cidade Velha (República de Cabo Verde)

Rodrigo Banha da Silva / João Pimenta / Clementino Amaro

1801 Algumas considerações sobre espólio não cerâmico recuperado no Largo de Jesus (Lisboa) Carlos Boavida

1815 Adereços de vidro, dos séculos XVI-XVIII, procedentes do antigo Convento de Santana de Lisboa (anéis, braceletes e contas)

Joana Gonçalves / Rosa Varela Gomes / Mário Varela Gomes

1837 Da ostentação, luxo e poder à simplicidade do uso quotidiano: arqueologia e simbologia de joias e adornos da Idade Moderna Portuguesa Jéssica Iglésias

1849 Os amuletos em Portugal - dos objetos às superstições: o coral vermelho Alexandra Vieira

1865 Cerâmicas de Vila Franca de Xira nos séculos XV e XVI Eva Pires

1879 «Não passa por teu o que me pertence». Marcas de individualização associadas a faianças do Convento de Nossa Senhora de Aracoeli, Alcácer do Sal Catarina Parreira / Íris Fragoso / Miguel Martins de Sousa

1891 Cerâmica de Leiria: alguns focos de produção

Jaqueline Pereira / André Donas-Botto

1901 Os Fornos na Rua da Biquinha, em Óbidos Hugo Silva / Filipe Oliveira

1909 A casa de Pêro Fernandes, contador dos contos de D. Manuel I: o sítio arqueológico da Silha do Alferes, Seixal (século XVI) Mariana Nunes Ferreira

1921 O Alto da Vigia (Sintra) e a vigilância e defesa da costa Alexandre Gonçalves / Sandra Santos

1937 O contexto da torre sineira da Igreja de Santa Maria de Loures Paulo Calaveira / Martim Lopes

1949 A Necrópole do Hospital Militar do Castelo de São Jorge e as práticas funerárias na Lisboa de Época Moderna Susana Henriques / Liliana Matias de Carvalho / Ana Amarante / Sofia N. Wasterlain

1963 SAND - Sarilhos Grandes Entre dois Mundos: o adro da Igreja e a Paleobiologia dos ossos humanos recuperados

Paula Alves Pereira / Roger Lee Jesus / Bruno M. Magalhães

1975 Expansão urbana da vila de Cascais no século XVII e XVIII: a intervenção arqueológica na Rua da Vitória no 15 a 17

Tiago Pereira / Vanessa Filipe

1987 Novos dados para o conhecimento do Urbanismo de Faro em época Moderna Ana Rosa 
1995 Um exemplo de Arqueologia Urbana em Alcoutim: o Antigo Edifício dos CTT Marco Fernandes / Marta Dias / Alexandra Gradim / Virgílio Lopes / Susana Gómez Martínez

2007 Palácio dos Ferrazes (Rua das Flores/Rua da Vitória, Porto): a cocheira de Domingos Oliveira Maia

Francisco Raimundo

2021 As muitas vidas de um edifício urbano: História, Arqueologia e Antropologia no antigo Recreatório Paroquial de Penafiel Helena Bernardo / Jorge Sampaio / Marta Borges

2035 O convento de Nossa Senhora da Esperança de Ponta Delgada: o contributo da arqueologia para o conhecimento de um monumento identitário João Gonçalves Araújo / N’Zinga Oliveira

2047 Arqueologia na ilha do Corvo... em busca da capela de Nossa Senhora do Rosário Tânia Manuel Casimiro / José Luís Neto / Luís Borges / Pedro Parreira

2059 Perdidos à vista da Costa. Trabalhos arqueológicos subaquáticos na Barra do Tejo Jorge Freire / José Bettencourt / Augusto Salgado

2071 Arqueologia marítima em Cabo Verde: enquadramento e primeiros resultados do projecto CONCHA

José Bettencourt / Adilson Dias / Carlos Lima / Christelle Chouzenoux / Cristóvão Fonseca / Dúnia Pereira / Gonçalo Lopes / Inês Coelho / Jaylson Monteiro / José Lima / Maria Eugénia Alves / Patrícia Carvalho / Tiago Silva

2085 Trabalhos arqueológicos na Cidade Velha (Ribeira Grande de Santiago, Cabo Verde): reflexões sobre um projecto de investigação e divulgação patrimonial André Teixeira / Jaylson Monteiro / Mariana Mateus / Nireide Tavares / Cristovão Fonseca / Gonçalo C. Lopes / Joana Bento Torres / Dúnia Pereira / André Bargão / Aurélie Mayer / Bruno Zélie / Carlos Lima / Christelle Chouzenoux / Inês Henriques / Inês Pinto Coelho / José Lima / Patrícia Carvalho / Tiago Silva

2103 A antiga fortificação de Quelba / Khor Kalba (E.A.U.). Resultados de quatro campanhas de escavações, problemáticas e perspectivas futuras Rui Carita / Rosa Varela Gomes / Mário Varela Gomes / Kamyar Kamyad

2123 Colónias para homens novos: arqueologia da colonização agrária fascista no noroeste ibérico Xurxo Ayán Vila / José Mạ . Señorán Martín 


\title{
O MUSEU UNIVERSITÁRIO COMO MEDIADOR ENTRE A CIÊNCIA E A SOCIEDADE: O EXEMPLO DA SECÇÃO DE ARQUEOLOGIA NO MUSEU DE HISTÓRIA NATURAL E DA CIÊNCIA DA UNIVERSIDADE DO PORTO (MHNC-UP)
}

\author{
Rita Gaspar ${ }^{1}$
}

\begin{abstract}
RESUMO
Os museus universitários têm uma responsabilidade acrescida na posição de mediadores entre a produção de conhecimento científico e a sua transferência para os diferentes públicos. Ainda que inicialmente mais centralizados no apoio ao ensino, atualmente têm uma missão mais alargada de transferência de conhecimento produzido na academia para a comunidade onde se inserem. Serão aqui apresentados alguns exemplos de abordagens desenvolvidas na secção de Arqueologia e Etnografia do Museu de História Natural e da Ciência da Universidade do Porto ao longo da história da instituição.

Palavras-chave: Museu universitário, Coleções arqueológicas, Transferência de conhecimento.
\end{abstract}

\begin{abstract}
University museums have an increased responsibility, as mediators between the production of scientific knowledge and its transfer to different audiences. Although they were initially more focused on supporting teaching activities, currently they have the broader mission of transferring knowledge produced in university to the community where they operate. Will be presented some examples of approaches developed in the Archaeology and Ethnography section of the Natural History and Science Museum of the University of Porto throughout the institution's history.

Keywords: University museum, Archaeological collections, Knowledge transfer.
\end{abstract}

\section{INTRODUÇÃO}

Os museus, enquanto instituições detentoras de coleções, articulam a salvaguarda do património com a comunicação do mesmo (Bruno, 1997). Aliam a produção e sistematização do conhecimento, independentemente da disciplina representada, à salvaguarda dos resultados e processos e sua comunicação, numa multiplicidade de formas. O potencial de intervenção dos museus é, pois, bastante vasto.

O envolvimento dos museus com o seu público cria um incentivo à participação, criando uma sociedade mais sensibilizada e empenhada. O seu papel transformador e de responsabilidade social é de extrema importância e deve ser tido em conta aquando da interação com as comunidades. Os museus universitários, apesar das suas especificidades, não são uma exceção. Efetivamente, os museus universitários, ainda que no seio de uma instituição de ensino, têm hoje uma missão mais alargada, também de envolvimento com as comunidades onde se inserem e com os públicos que as visitam.

O Museu de História Natural e da Ciência da Universidade do Porto (MHNC-UP) foi constituído for- 
malmente em 2015, resultando da unificação do Museu de História Natural (MHNFCP) e do Museu da Ciência (MCFCP) da Faculdade de Ciências da Universidade do Porto. Ainda que o MCFCP tenha sido criado apenas em 1996 o MHNFCP resultou da união dos quatro museus-laboratórios da Faculdade de Ciências, criada em 1911. Estes museus de departamento, o Museu e Laboratório de Antropologia, o Museu de Zoologia, o Museu do Instituto de Botânica Gonçalo Sampaio e o Museu de Mineralogia e Estratigrafia, eram detentores de importantes coleções, tendo tido um papel fundamental no apoio ao ensino no seio da academia.

Iremos centrar este artigo no papel que este museu universitário, nomeadamente as coleções de Arqueologia da secção de Arqueologia e Etnografia, teve ao longo dos tempos, no envolvimento entre a universidade e o público, num esforço de divulgar e promover a ciência.

\section{MUSEU UNIVERSITÁRIO - MISSÃO TRIPARTIDA}

As universidades foram das primeiras instituições públicas a acolher coleções. Entre elas surge o exemplo do Ashmolean Museum da Universidade de Oxford, aberto no século XVII e tido como o mais antigo museu universitário (Simpson, 2019). Através das coleções, constituídas na sua maioria para utilização em ambiente de ensino, a universidade conseguia cumprir o seu principal propósito de transmitir conhecimento, ainda que apenas a uma pequena franja da sociedade. Ao longos dos tempos, a democratização do ensino alargou também o âmbito da comunicação de conhecimento e os museus universitários encontram-se agora abertos a vários públicos, promovendo o envolvimento das comunidades em que se inserem, mas também inserindo-se nas dinâmicas associadas aos grandes movimentos turísticos do século XXI.

Como tão bem refere Simpson (2019), os museus universitários têm uma missão tripartida que define, atualmente, a sua atuação:

-Ensino, transmissão de conhecimento. Este processo poderá ser, ou não, apoiado em objetos e coleções. No entanto, a utilização de objetos incrementa o potencial de compreensão da mensagem por parte do recetor, ao mesmo tempo que multiplica as abordagens possíveis aos temas a explorar. As coleções podem inclusive ser utilizadas em abordagens multidisciplinares, em cenários de ensino formal, mas também em ensino informal.

- Investigação, geração de conhecimento. As coleções universitárias têm vindo a ser revisitadas, sendo excelentes repositórios para a ciência atual. As aproximações e abordagens são constantemente atualizadas o que permite um incremento da produção de conhecimento a partir das coleções. O cruzamento de disciplinas potencia, inclusive, a obtenção de resultados extraordinários. As coleções biológicas arqueológicas, nomeadamente, estão a ser utilizadas na caracterização da população humana antiga a nível molecular e das suas dinâmicas, com grande sucesso. Estas coleções devem estar, com as devidas questões da salvaguarda da sua integridade asseguradas, acessíveis para a aplicação de novos métodos e técnicas científicas, de forma a responder a novas questões que agora se colocam.

- Envolvimento e impacto na sociedade. Existem vários exemplos de estratégias levadas a cabo pelos museus universitários de modo a potenciar o envolvimento da comunidade. Em Portugal muito se tem feito também e é fundamental que os museus universitários se assumam enquanto os mediadores entre a comunidade científica, que produz conhecimento nas universidades, e os diferentes públicos. O seu papel é traduzir este conhecimento, associado a uma linguagem mais técnica, e torná-lo acessível aos diferentes públicos. O museu universitário tem ainda a especial missão de "apresentar" a universidade à comunidade. Algumas universidades desenvolveram, inclusive, a sua identidade distintiva recorrendo ao património existente nos seus próprios museus (Simpson, 2012). O museu universitário pode, hoje, constituir-se como um mediador entre a instituição e os públicos (geral ou especializado), salientando a importância da investigação e ações que enceta e promovendo a fruição do seu património.

Expressa na Declaração de Halle, de 16 de abril de 20oo, elaborada por representantes de 12 universidades europeias, está a importância das coleções universitárias, apresentadas como "recursos ativos para o ensino e investigação" e "arquivos históricos únicos e insubstituíveis". No mesmo documento assume-se o potencial de utilização destas coleções junto de um público mais alargado, constituindo 
como testemunhos do papel das universidades na "definição e interpretação da nossa identidade cultural" (https://www.universeum-network.eu/ the-declaration-of-halle/).

\section{1. $O$ ensino no seu código genético}

A utilização de coleções no processo de transmissão de conhecimentos facilita a compreensão de conceitos que de outro modo poderiam permanecer abstratos. A observação do objeto tridimensional, a possibilidade de observação de séries e a integração dos objetos em contextos, possibilitadas pelas coleções de museu, aumentam o potencial pedagógico das mesmas, independentemente do objetivo da sua constituição.

De acordo com Simpson (2012), o envolvimento com o objeto continua a ser uma estratégia fundamental no processo de aprendizagem. $\mathrm{O}$ autor afirma mesmo que é na sua capacidade de estabelecer ligações entre distintas áreas de saber que reside o elevado potencial pedagógico dos objetos (Simpson, 2019). As coleções dos museus universitários são, na generalidade dos casos, iniciadas com o objetivo de apoiar o ensino e a comunidade académica. Alguns casos existem também de constituição com base em coleções de gabinetes de curiosidades (Gil, 2005). De qualquer modo, as coleções refletem também a história da instituição detentora e, no caso que aqui iremos destacar, o modo como a própria instituição interagiu com os seus diferentes públicos e utilizadores.

Enquadrados numa universidade, os museus que constituem atualmente o MHNC-UP estavam intimamente ligados aos sectores de ensino e investigação da Faculdade de Ciências (Gil, 2005). As coleções que inicialmente os constituíam encontram-se muito vocacionadas para o ensino, numa perspetiva de representação dos conteúdos lecionados. A secção de Arqueologia e Etnografia não é exceção, como veremos, ainda que a componente da investigação esteja fortemente representada.

\section{CONSTITUIÇÃO DAS COLEÇÕES}

Tendo em conta a necessidade de resposta aos três tipos de público, tão distintos entre si (público geral, estudantes e investigadores), são também constituídos diferentes tipos de coleções nos museus universitários (Gil, 2005). Também no MHNC-UP este processo está bem patente no devir da instituição. A par da seleção de exemplares emblemáticos e bem conservados para apresentação pública, nomeadamente em exposição, constituíram-se coleções de ensino, que incluíam, com grande frequência, réplicas e modelos de determinados exemplares e mesmo material didático bidimensional como slides de projeção ou "reportagens". As coleções científicas foram constituídas de acordo com os projetos a decorrer, sendo hoje em dia bastante procuradas por investigadores nacionais e estrangeiros para a integração em novos estudos e análises. Estas coleções de Arqueologia foram sendo revisitadas ao longo de décadas e estão hoje referenciadas nas mais atuais dinâmicas de investigação como sejam a domesticação de espécies animais ou o estudo de população humana antiga, através de ADN ou isótopos.

Á semelhança do que acontece noutros museus universitários, a génese das coleções é também diversa no MHNC-UP. De entre os vários casos possíveis, incluindo a integração de instituições ou a herança de coleções que posteriormente levam à criação de museus, o MHNC-UP surge de um longo processo ao longo do qual os vários departamentos e institutos criaram os seus próprios museus. Efetivamente, uma parte das coleções foi constituída com o objetivo de transmitir o conhecimento científico, com um propósito didático. Criada em 1911, a Universidade do Porto, partindo da estrutura da anterior Academia Politécnica, dotou-se de algumas infraestruturas com vista a apoiar o ensino. Entre elas o Museu e Laboratório de Antropologia, criado por António Mendes Correia. No caso das coleções arqueológicas, elas surgem no contexto do Museu e Laboratório de Antropologia, criado por António Mendes Correia em 1912, imediatamente na sequência da reforma universitária de 1911, e do Instituto de Antropologia, criado um pouco mais tarde, em 1923.

Inicialmente mais vocacionado para a Antropologia biológica, rapidamente o acervo do museu compreendeu também coleções de Arqueologia e Etnografia. É notória a preocupação de adquirir elementos que ajudassem a estruturar a narrativa pedagógica, ainda que muitas das aquisições cumprissem uma função dupla, também de comunicação com o público. Serão aqui apresentados alguns exemplos.

\subsection{Modelos e réplicas}

Os modelos e réplicas foram, desde sempre, um recurso ao serviço do ensino tanto na Academia Politécnica como na Universidade do Porto (Vieira et al., no prelo). A produção ou aquisição destes elemen- 
tos permitia, por um lado, ter no museu peças que, de outro modo, não estariam disponíveis (como sejam, por exemplo, réplicas de fósseis humanos ou de arte rupestre móvel e parietal) e, por outro lado, ilustrar conceitos (como seja o caso do Homo afer taganus). A existência destas peças permitiu que durante todo o século XX, e ainda hoje, os diferentes públicos tivessem acesso a este tipo de património. A aquisição destes elementos a diversos comptoires é complementada pela execução de réplicas, realizadas internamente.

Ainda da fase da Academia Politécnica é possível identificar réplicas em gesso de dois machados de pedra polida, cuja etiqueta faz a referência a Estácio da Veiga. No entanto, a quase totalidade dos modelos e réplicas foi adquirida a partir da década de 1920, já no âmbito da Universidade do Porto. Um dos conjuntos mais antigos corresponde ao das réplicas em gesso, realizadas internamente, a partir do conjunto arqueológico recolhido pelos padres Rafael Rodrigues e José Brenha em Carrazeda do Alvão em 1895 (Rodrigues, 1895). Trata-se de um conjunto de figuras zoomórficas e antropomórficas, bem como algumas placas com gravuras e a designada escrita do Alvão. Terá sido realizado por volta de 1927, indicação patente em alguns dos moldes em gesso. Desta fase surge ainda uma réplica de uma pequena placa gravada de Glozel (França), sítio que foi utilizado à época como referência para no polémico estudo da escrita do Alvão.

Da década de 1930 existe um conjunto, também de réplicas em gesso, de pegadas, digitações e alguma arte rupestre de grutas como sejam Tuc d'Audoubert e Bedeilhac. Este conjunto foi oferecido por Henri Begouen.

Ainda na mesma década, na sequência das escavações arqueológicas realizadas nos sítios de Muge, Mendes Correia encomenda um modelo do seu Homo afer taganus ao artista madeirense Agostinho Rodrigues (Figura 1), materializando assim a sua teoria relativamente à presumível nova espécie humana identificada no nosso território (Vieira et al., no prelo). Efetivamente, as réplicas integradas na temática da evolução humana são em grande número, tendo sido adquiridas desde a década de 1950. Permitiam aos diferentes utilizadores do museu a observação das características distintivas ao nível sobretudo do crânio de cada fóssil humano representado. Inicialmente vocacionadas para o ensino da evolução humana, estas réplicas vão sendo atualizadas ao ritmo das atualizações técnicas da sua produção bem como ao ritmo das descobertas científicas realizadas, e no último quartel do século XX é colocada em exposição no museu uma secção de evolução humana, onde se integra também um painel com as pegadas de Laetoli e um conjunto de réplicas do fóssil diretor Australopithecus afarensis conhecido por Lucy. A última aquisição realizada, em 2019, foi uma réplica do esqueleto conhecido como Neo, o mais completo identificado como Homo naledi. A preocupação da atualização de conteúdos de acordo com a produção científica atribui a esta coleção um verdadeiro efeito mediador entre a ciência e o público.

Um outro conjunto considerável de réplicas, adquiridas, mas igualmente produzidas internamente, remete para utensílios em pedra lascada, pedra polida ou indústria óssea pré-histórica. Mais uma vez, nas réplicas adquiridas, estão representados elementos provenientes de jazidas emblemáticas como La Madeleine, Le Moustier ou Koobi Fora. Apenas na década de 1980, já após a reestruturação do museu posterior ao incêndio de 1974, são incorporadas réplicas de materiais de cronologia romana, como sejam fíbulas, lucernas e aras votivas, provenientes do Museu Monográfico de Conimbriga.

Ainda que atualmente se privilegie o original em detrimento da réplica, os modelos conhecem uma nova valorização. O hiper-realismo conseguido por alguns artistas especializados na representação dos vários elementos da grande família humana permite transmitir o conhecimento de um modo único e próximo do público. Tomamos como exemplo os modelos recentemente adquiridos para a futura exposição permanente do MHNC-UP, de Kennis e Kennis Reconstructions. Estes modelos surgem como um excelente modo de aproximar a ciência e o cidadão.

\subsection{A coleção Museus de Berlim}

O exemplo da Coleção Museus de Berlim é paradigmático no que refere á utilização de objetos e coleções no ensino universitário, paralelamente ao engajamento da comunidade e à construção de uma identidade de grupo.

Esta coleção foi constituída em 1925 em Berlim, através de uma recolha junto dos Staatliche Museen zu Berlin - Museus Estatais de Berlim, sob coordenação do arqueólogo Walter Andrae. Este processo decorre de uma longa negociação diplomática entre os estados Português e Alemão, na sequência do aprisionamento do navio Cherusquia que transportava 
a coleção resultante das escavações de Assur, entre outros, em 1916. Este episódio, que levou á participação de Portugal na $1^{\underline{a}}$ Guerra Mundial, é sobejamente conhecido (Morais; Gaspar; Reis, 2019). Em 1926, após acordo entre os estados, decorre a troca da coleção de Assur por uma coleção de estudo com peças que, segundo as palavras de Walter Andrae, representassem "bons exemplos das linhas históricas” (Cholidis, 2019). Esta coleção marcadamente didática, recolhida dos vários museus estatais de Berlim, chega ao Porto em 1927 e é imediatamente integrada no Museu de Arqueologia Histórica da Faculdade de Letras da Universidade do Porto (FLUP). Posteriormente, em 1940, foi transferida para a Faculdade de Ciências (FCUP) e integrada no Museu de Antropologia, na sequência do encerramento da $1^{\underline{a}}$ FLUP. Em ambas as faculdades a coleção foi utilizada como apoio às aulas. Nesta coleção, arqueológica e etnográfica, existem conjuntos provenientes dos cinco continentes sendo representativos de algumas culturas como sejam a azteca e chiriqui da Meso-América, da Mesopotâmia, do antigo Egipto entre muitas outras. A subcolecção egípcia (Figura 2), especificamente, tem um papel especial na identidade da universidade. Qualquer aluno que se tenha formado nas últimas décadas na FCUP se lembra da visita de estudo realizada à coleção. De tal modo a Coleção Museus de Berlim e a sua história pertencem ao ADN da Universidade do Porto que esta foi selecionada para a realização de uma exposição temporária (2019/2O2O) - Culturas e Geografias - comemorativa do centenário da primeira FLUP. Esta coleção é um perfeito exemplo do envolvimento de uma comunidade em torno de uma coleção museológica.

\subsection{A coleção de Muge}

Outra coleção emblemática do MHNC-UP é a coleção de Muge, que reúne vários sítios mesolíticos. Decorrente das intervenções dirigidas por Mendes Correia na década de 1930, esta coleção detém um extenso conjunto de indivíduos de cronologia mesolítica, a par de restos faunísticos e um alargado conjunto de indústria lítica. Foi uma coleção constituída a partir de um processo de investigação, tendo sido revisitada por várias gerações de investigadores desde a sua entrada no Museu de Antropologia, atual MHNC-UP. Ainda hoje é frequentemente procurada por investigadores de diferentes áreas disciplinares, com novas questões e metodologias de trabalho. Exemplo de que estas coleções nunca se esgotam em termos de abordagem é o trabalho que tem vindo a ser desenvolvido por Rita Peyroteu Sterna (2016) recorrendo a estudos moleculares para caracterizar esta população humana antiga.

Também a Coleção Baixo Sabor, incorporada no MHNC-UP em 2015, é frequentemente requisitada para investigação. Compreende a componente bio-arqueológica (esqueletos humanos, restos faunísticos e restos antracológicos e carpológicos) resultante das escavações arqueológicas no vale do Sabor entre 2008 e 2014. Entre os inúmeros estudos que têm sido realizados e publicados salientamos o exemplo de Alice Toso (2018), que, partindo da análise de isótopos, aborda a questão da dieta alimentar destas populações e a implicação desta na organização socio-cultural das comunidades. Os resultados destes estudos facilmente poderão ser divulgados junto do público não especializado utilizando o museu como mediador do processo de transmissão de conhecimento.

\section{ACESSIBILIDADE DE COLEÇÕES}

O acesso ás coleções é uma das questões mais prementes. Pretende-se que as coleções fiquem acessíveis aos diferentes tipos de público de modo a potenciar as leituras construídas e a fomentar respostas criativas nas gerações futuras. Desde 2016 que o MHNC-UP integra a Portuguese Research Infrastruture of Scientific Collections - PRISC (https:// www.prisc.pt/) tendo como parceiros o Museu Nacional de História Natural e da Ciência da Universidade de Lisboa e o Museu de Ciência da Universidade de Coimbra. Os três museus universitários estão comprometidos com a preservação e acessibilidade das coleções científicas portuguesas.

Neste âmbito tem sido realizada uma recuperação das reservas e das coleções, com respetivo acondicionamento dos objetos e coleções seguindo as normas atuais. Os inventários encontram-se em fase de atualização e revisão, de modo a incrementar a utilização pelo público geral e investigadores. Este processo de reestruturação, que também implica a digitalização de coleções, permite generalizar o acesso aos objetos e potenciar as abordagens de estudo e usufruto das coleções. Esta profunda reestruturação da organização das coleções arqueológicas e etnográficas no MHNC-UP tem permitido uma atualização da estrutura das coleções de acordo com os parâ- 
metros normalizados utilizados por outros museus. Desde então foi possível aumentar o número de estágios curriculares, mestrados, doutoramentos e estudos realizados com base nas coleções do MHNC-UP, alargando as possibilidades de acesso da comunidade académica. A realização de empréstimos para exposições temporárias ou ações de divulgação pontuais são outro modo de transmitir conhecimento científico. É disso exemplo o protocolo de empréstimo temporário (2018-2020 e 2020-2022) da coleção proveniente do megalitismo do Crato, recolhida por Agostinho Farinha Isidoro. Estabelecido entre a Universidade do Porto e o Município do Crato, este protocolo tem tornado possível à população desse município tomar contacto e usufruir de um conjunto de materiais pré-históricos que de outro modo lhes estaria geograficamente distante. Este tipo de soluções tem sido replicado com outras entidades, fazendo com que o património do MHNC-UP se torne veículo de transmissão de conhecimento fora de portas.

\section{ENVOLVIMENTO COM A COMUNIDADE - ATIVIDADES DE DIVULGAÇÃO}

Inscrita na missão do MHNC-UP integra-se também a promoção da cultura científica. Como tal, nestes últimos anos têm sido realizadas várias atividades, desenvolvidas tendo em consideração os diferentes públicos participantes. As ações integradas e transversais às diferentes áreas disciplinares representadas no MHNC-UP envolvem os curadores e estabelecem a ponte entre a ciência e a comunidade. A arqueologia, no qual nos iremos centrar aqui, está também representada desenvolvendo atividades de cariz mais expositivo ou mais prático, numa tentativa de adaptação da transmissão de conhecimento. A participação na Noite Europeia dos Investigadores (NEI) em 2016 e 2107 foi estruturada a partir de atividades Hand on, de modo a que os participantes tirassem o máximo de partido da ação. Na transmissão de conhecimento privilegiou-se a experimentação (Figura 3 e 4).

Foram também desenhadas algumas atividades para participação nos programas da Ciência Viva - Agência Nacional para a Cultura Científica e Tecnológica. Tomamos como exemplo a ação Ao Leme com a Ciência Viva, que decorreu no verão de 2016. Com um foco muito específico no mar, a chamada à participação solicitava uma abordagem de sensibilização para a proteção dos oceanos. A abordagem definida na atividade desenvolvida pela secção de Arqueologia e Etnografia focou-se na importância da exploração dos recursos marinhos pelas comunidades humanas ao longo dos tempos, salientando a estreita relação de algumas comunidades com o mar. Exemplos como a produção de preparados piscícolas em época romana permitiram trabalhar tanto o tema de conservação dos oceanos como a vivência das comunidades, atividades económicas e técnicas utilizadas no passado.

Neste esforço de criar pontes com os vários públicos integra-se também a colaboração com outras entidades locais, na divulgação do património pertencente ao MHNC-UP. É o caso da Câmara Municipal do Porto, com a sua ação Um objeto e seus discursos por semana (Figura 5). Esta excelente iniciativa permite pôr em diálogo especialistas e público, em torno de um objeto e sua história e/ou significado.

O serviço educativo do MHNC-UP, estruturado em 2019 e coordenado pelo professor Nuno Teles, desenvolve um programa integrado, onde as ações promovidas desenvolvem-se em estreita colaboração com os curadores das coleções.

Num outro registo, o ano de 2020 irá ficar marcado definitivamente pela dinâmica das relações museu-público. O facto de, pela primeira vez no mundo, se terem confinado populações e cidades em massa, impedindo a deslocação das pessoas aos museus, levou ao reforço da presença destas instuições on line, numa tentativa de continuidade no envolvimento com os seus públicos. No MHNC-UP, em articulação com a Casa Comum, estabeleceu-se um programa de podcasts, que inclui a série Terras sem fim (https:// mhnc.up.pt/podcasts-terras-sem-fim/ ou https:// up.pt/casacomum/terras-sem-fim/, também disponíveis no Spotify), na qual são apresentadas as coleções de Arqueologia e Etnografia. Pretende-se, além de transmitir conhecimento de um modo alternativo, mas potencialmente mais difusor, desenvolver uma relação com diferentes públicos cativando-os a uma visita posterior ao museu.

Este material disponível on line poderá ser utilizado, futuramente, enquanto recurso de ensino pela comunidade escolar.

\section{CONCLUSÃO}

Sendo amplamente assumido o papel das coleções dos museus enquanto veículos de transmissão de 
saber, importa definir estratégias que permitam potenciar o acesso dos diferentes tipos de público às mesmas. O processo de envolvimento na comunidade pode ser conseguido através do estabelecimento de inúmeras estratégias, cabendo a cada instituição definir as abordagens junto da sua comunidade, que deverão passar pela inclusão dos diversos públicos e pelo estabelecimento de abordagens múltiplas. A compartimentação das disciplinas científicas não ajuda estes propósitos, logo uma abordagem integrada e integradora lança as sementes para o usufruto do museu por todos e para a implementação da criatividade enquanto motor da sociedade.

Os museus universitários surgem com uma responsabilidade acrescida, na posição de mediadores entre a produção de conhecimento científico e a sua transferência para os diferentes públicos. Não podemos deixar de concordar com Gil (2005, p. 49) quando indica que um dos objetivos dos museus universitários é "estudar, conservar e apresentar convenientemente as coleções que possui, usando-as em acções científico-pedagógicas da sua iniciativa ou em colaboração com outros organismos, com prioridade para os restantes departamentos universitários”.

No MHNC-UP implementam-se estratégias nesse sentido, assumindo este papel mediador. Foram aqui apresentados alguns exemplos ligados à Arqueologia.

\section{AGRADECIMENTOS}

Este artigo beneficiou da utilização da Infraestrutura Portuguesa de Coleções Científicas (Portuguese Infrastructure of Scientific Collections - PRISC.pt).

\section{BIBLIOGRAFIA}

BRUNO, M. C. O. A. (1997) - A indissolubilidade da pesquisa, ensino e extensão nos museus universitários. Cadernos de Sociomuseologia. Lisboa, 10, pp. 47-51

CHOLIDIS, Nadja (2019) - "Entregues a Portugal em troca dos achados de Assur.” Um capítulo da história museológica luso-alemã (1914-1927). In Morais, Rui; Gaspar, Rita; Reis, José da Costa, ed. Culturas e Geografias. Centenário da Faculdade de Letras da Universidade do Porto (1919-2019)/ Cultures and Geographies. Centenary of the Faculty of Arts and Humanities of the University of Porto (1919-2019). Porto: Arte e Ciência - Universidade do Porto, pp. 65-96.

GIL, Fernando Bragança (2005) - Museus universitários: sua especificidade no âmbito da museologia. In: Semedo, Alice; Silva, Armando Coelho da, coord., Coleções de ciências fisicas e tecnológicas em museus universitários: home- nagem a Fernando Bragança Gil. Porto: Faculdade de Letras da Universidade do Porto, pp. 33-52.

MORAIS, Rui; GASPAR, Rita; REIS, José da Costa, ed. Culturas e Geografias. Centenário da Faculdade de Letras da Universidade do Porto (1919-2019)/Cultures and Geographies. Centenary of the Faculty of Arts and Humanities of the University of Porto (1919-2019). Porto: Arte e Ciência Universidade do Porto.

RODRIGUES, Rafael (1895) - Dolmens ou antas de Vila Pouca de Aguiar. O Arqueólogo Português. Lisboa. Série I, Vol. 1, pp. 36-37.

SIMPSON, Andrew (2012) - Modelling governance structures for university museums and collections. In: Jandl, S. \& Gold, M., eds., A Handbook for Academic Museums: Beyond Exhibitions and Education. Edinburgh \& Boston: Museums Etc, pp. 178-218.

SIMPSON, Andrew (2019) - Museums and collections, epistemic convergence and higher education. In: Bueno, David et al., ed, Humanities and higher education: synergies between science, technology and humanities. Barcelona: Global University Network for Innovation, pp. 209-215.

STERNA, Rita Peyroteo (2016) - On Death in the Mesolithic or the Mortuary Practices of the Last Hunter-Gatherers of the South-Western Iberian Peninsula, $7^{\text {th }}-6^{\text {th }}$ Millennium BCE. Uppsala: Uppsala Universitet.

TOSO, Alice (2018) - Diet in Medieval Portugal: exploring inter-faith and social dynamics through stable isotope analysis. PhD thesis, University of York.

VIEIRA, Cristiana; MUCHAGATA, João; GASPAR, Rita; GONÇALVES, Helena; MATEUS, Simão, FONSECA, Maria João (no prelo) - From abstractionism to hyperrrealism: 150 years of biological models and replicas at the Museu de História Natural e da Ciência da Universidade do Porto. Edinburgh: Archives of Natural History. 

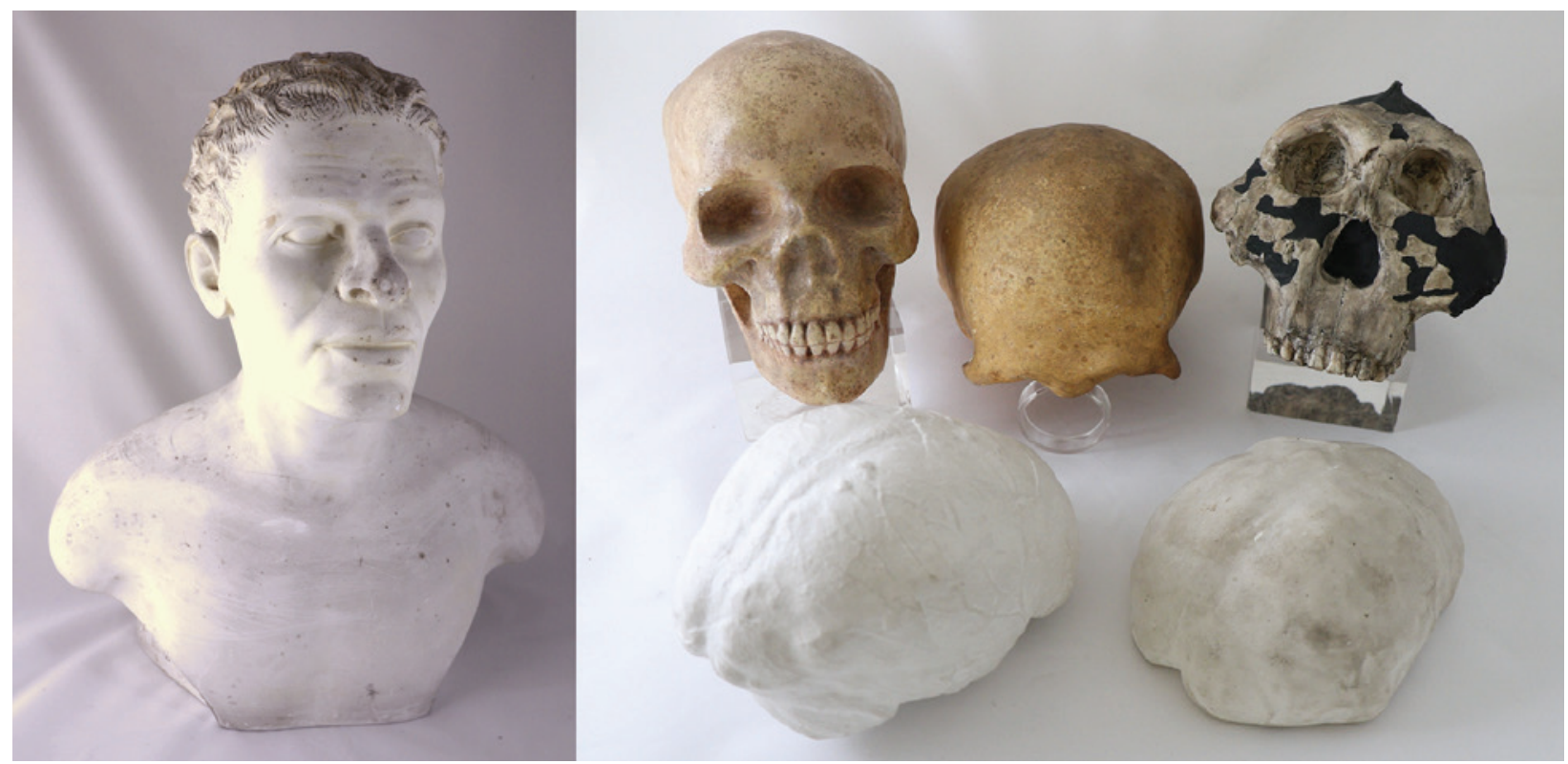

Figura 1 - Busto de Homo afer taganus por Agostinho Rodrigues (esquerda) e pequena seleção de replicas de crânios e modelos de cérebros adquiridos Anatomical Laboratory of Charles H. Ward (direita). Créditos MHNC-UP.

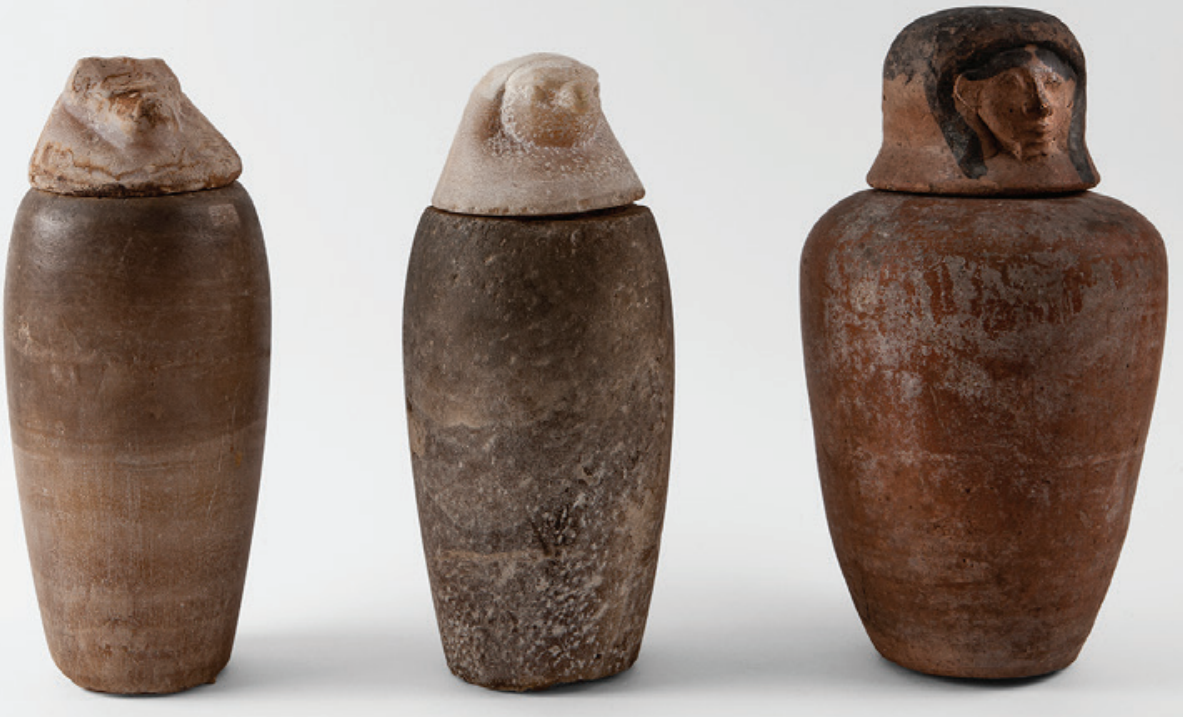

Figura 2-Conjunto de vasos de vísceras pertencentes à Coleção Museus de Berlim. Créditos MHNC-UP / José Eduardo Cunha. 


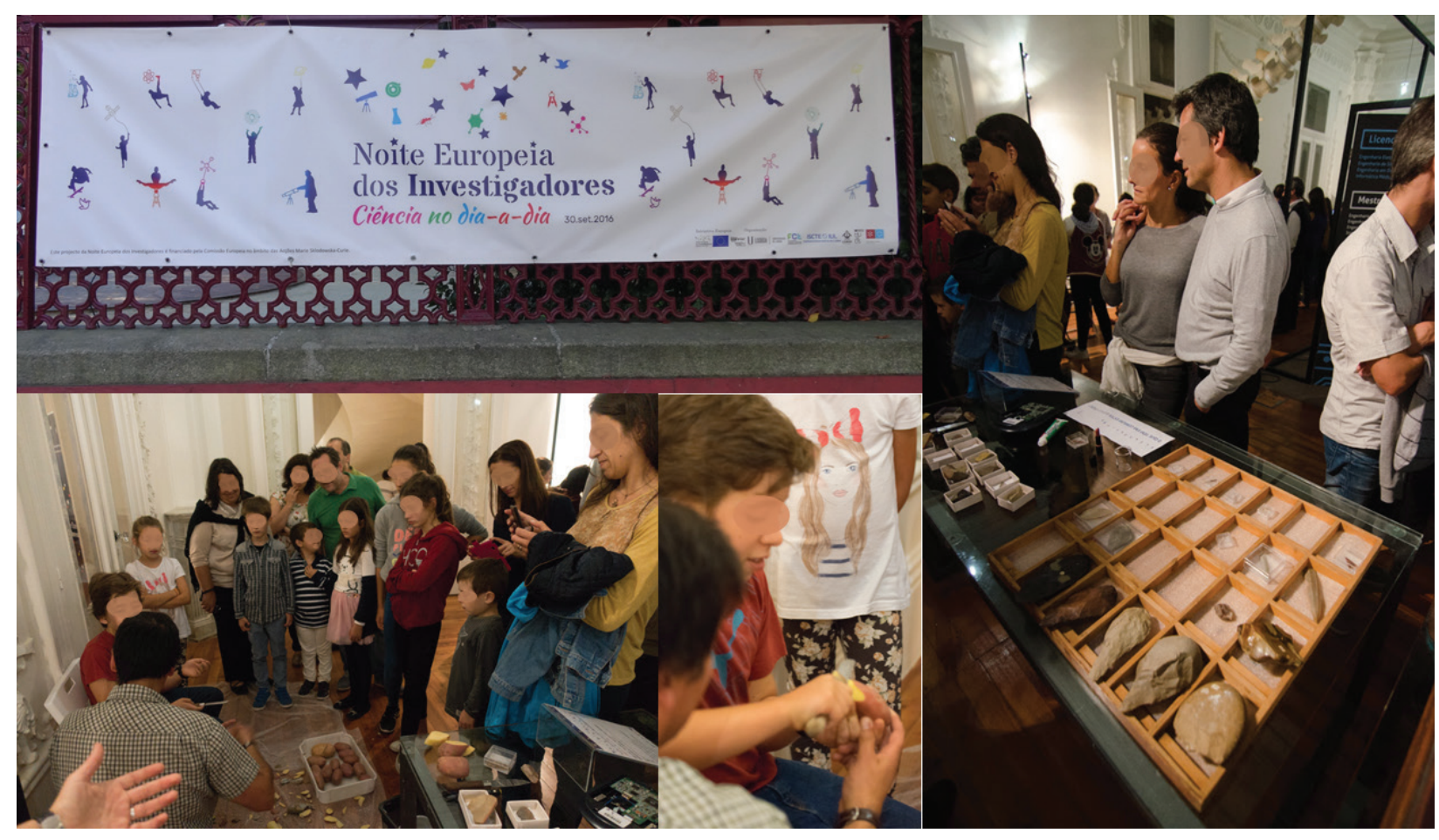

Figura 3-Participação na Noite Europeia dos Investigadores em 2016 onde se discutiu a aplicação do sílex ao longo dos tempos. A atividade Hands on permitia o contacto dos participantes com a as técnicas de talhe. Créditos MHNC-UP / Ricardo Lopes.

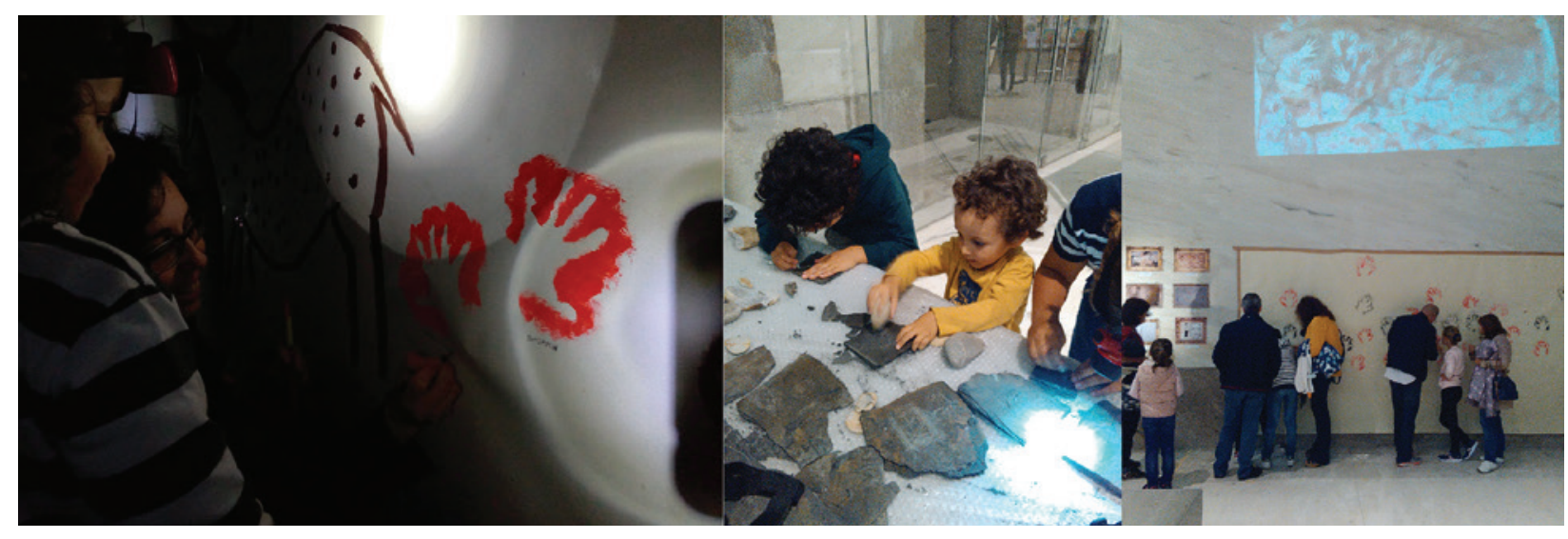

Figura 4 - Atividade preparatória para a Noite Europeia dos Investigadores (NEI) em 2017 realizada num estabelecimento do pré-escolar local (esquerda) e participação na NEI (centro e direita) onde se apresentaram técnicas de representação gráfica desde a Pré-História. A atividade Hands on permitiu o contacto dos participantes com as técnicas e materiais envolvidos na pintura e na gravura rupestre. Créditos MHNC-UP. 


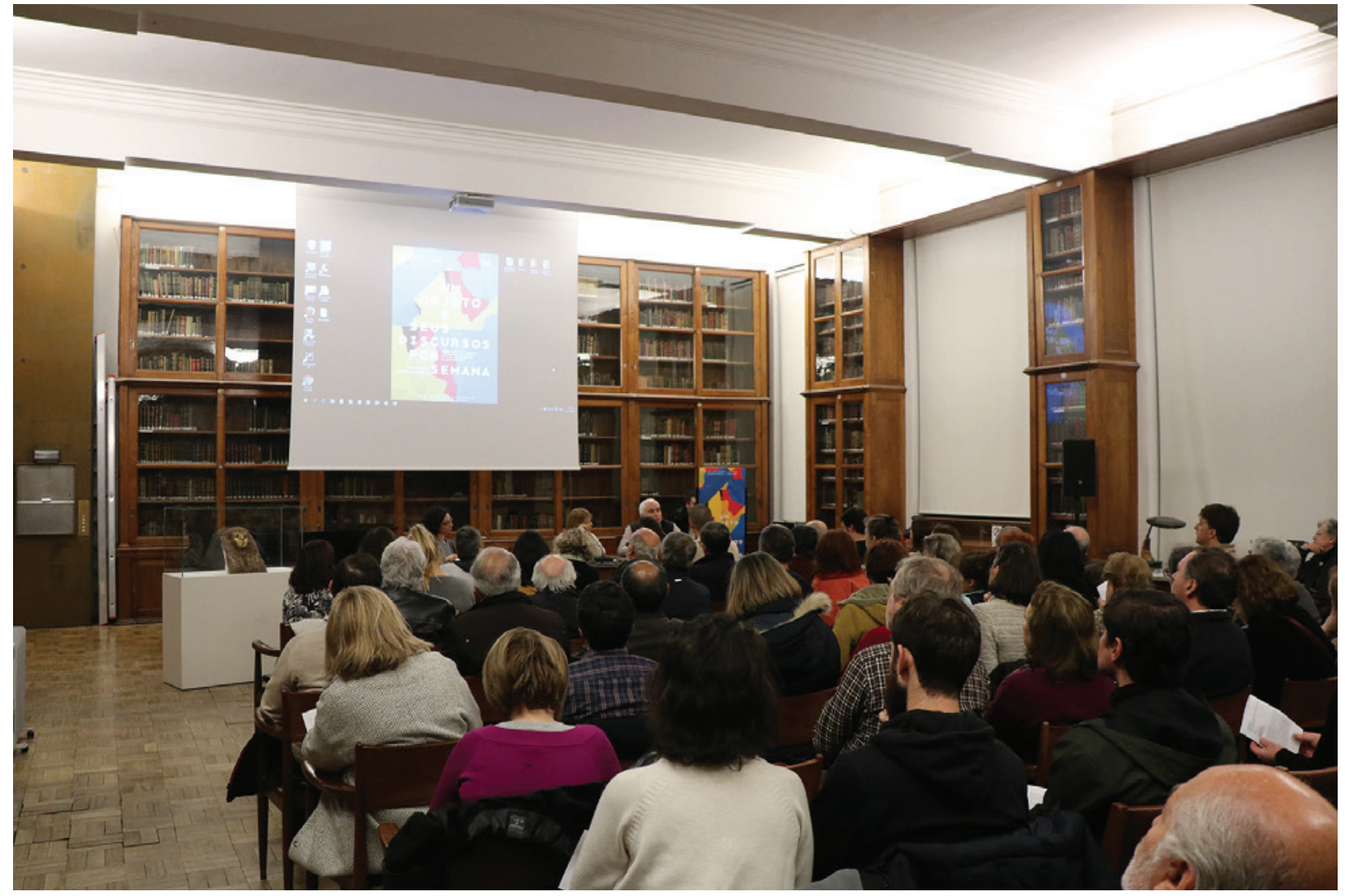

Figura 5- Sessão de Um objeto e seus discursos realizada em novembro de 2019, em torno da Máscara egípcia do MHNC-UP. Créditos MHNC-UP. 



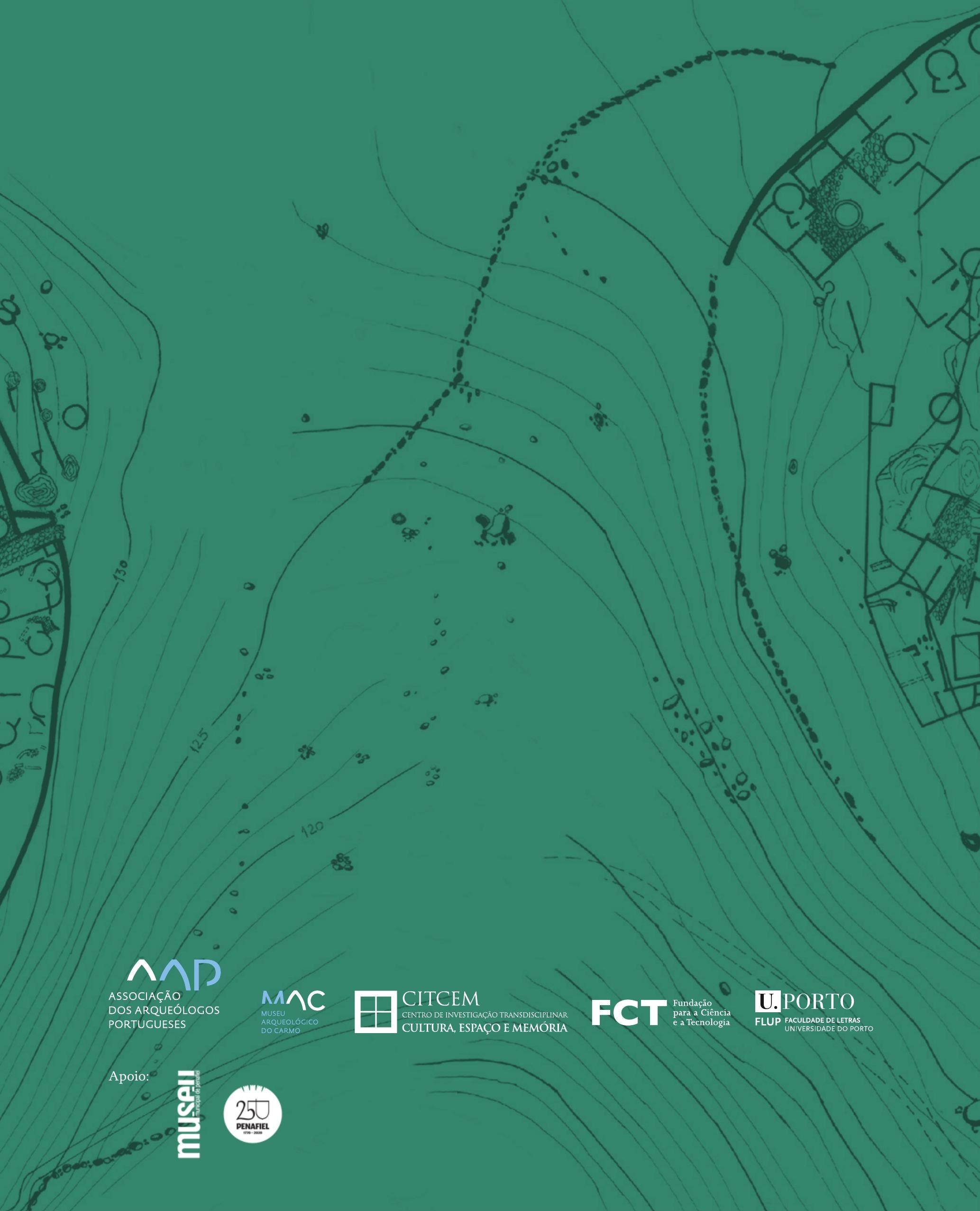

